$\left(\begin{array}{l}\mathrm{J} . S o c . C o s m e t . C h e m . J p n \\ \text { 報 } \\ 32 \text { 文 }\end{array}\right.$

報 32 (2) $147-152(1998)$

\title{
低角度レーザー光散乱検出器を用いたサイズ排除クロマトグラフィーによる ヒアルロン酸の分子量分布測定 $\dagger^{1}$
}

渋 谷 満, 大石多恵子, 山本 信 也, 長 谷 部 進 資生堂 掛川工場 製薬部 $\dagger^{2}$

低角度レーザー光散乱検出器（LALLS）を用いたサイズ排除クロマトグラフィー（SEC/LALLS）に より，市販化粰品用粉末及び医薬品用注射剂中のヒアルロン酸（HA）の平均分子量（Mw）と分子量 分布を測定した。用いたカラムは網目状に架橋された親水性樹脂からなる TSK gel G 6000 PW $\mathrm{cm} ）$ を 4 本連結し，これに移動相として $0.2 \mathrm{M}$ 硫酸ナトリウム水溶液を毎分 $1.0 \mathrm{ml}$ で流した。この SEC

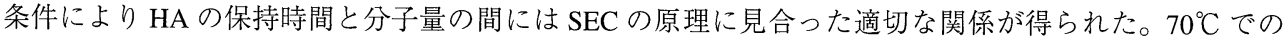
加熱処理による HA の低分子化の過程については高分子量になるにつれて分解率が高くなることを認め た。測定した 8 種の化粧品用 $\mathrm{HA}$ 粉末の $\mathrm{Mw}$ と粘度平均分子量は良く一致した。 $\mathrm{HA}$ 含有注射剤からの 前処理は移動相に希釈するだけであり，この溶液を直接 SEC に注入した。今回測定した 8 種の化粧品 用 HA 粉末と 4 種の医薬品用 HA 注射剤の中では，注射剤からの HA が最も低い分子量分散度を示した。 SEC/LALLS はHA とこの関連製剂の分子量分布測定に有用であることがわかった。

\section{1. 緒言}

ヒアルロン酸ナトリウム（HA）は生体内で高 い水分保持機能を持ち，組織に柔軟性を与えるな ど重要な性質を有する酸性ムコ多糖である。これ らの特性に注目して鶏冠より抽出した HA が高級 スキンケア化粧品の一部に処方され始めてから既 に 15 年が経過した。その間には赤坂らりより微 生物を用いた HAの工業的生産技術が開発されて からは，発酵法による HA が安価に供給されるよ うになり，化粧品への処方が広く普及した。また 医薬品にも HA の用途は広がっており, 点眼剤, 膝・肩の関節内注射剂, 眼科手術補助剂として利 用されている。このように多岐に渡る需要から, 現在ではHAの製造業者は抽出法と発酵法を含め, 国内で数社に及んでいる。

$\dagger^{1}$ 1997. 12.5 受理

$\dagger^{2}$ ₹436-0047 静岡県掛川市長谷 $1120: 1120$, Nagaya, Kakegawa, Shizuoka 436-0047, Japan
多方面に渡って利用されるようになった HAの 評価としては先ずその純度があり, 特に不純物と しての蛋白質, さらに医薬品用 HA については発 熱性物質であるエンドトキシンの検出の有無が問 題とされる。また一方で HA の特異的性質である 水和性, 粘弾性はその分子量に依存することが知 られており2)，使用する HA の特性を把握するた めに分子量評価を行うことは極めて重要である。 混合系での HA の分子量測定にはサイズ排除クロ マトグラフィー（SEC）が多用されており, 最近

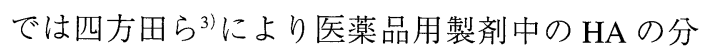
子量評価がなされている。これによれば, 排除限 界分子量の異なる 2 本の $30 \mathrm{~cm}$ カラムの使用にお いて重量平均分子量 $(\mathrm{Mw})$ が $1.5 \times 10^{6}$ 以上の $\mathrm{HA}$ は排除限界に達していることが報告されている。 そこで著者らは, より十分な排除限界分子量を示 すカラム条件を用いて低角度レーザー光散乱検出 器（LALLS，LS）を備えたSECにより市販化粧 品用 $\mathrm{HA}$ 粉末の $\mathrm{Mw}$ と分子量分布を測定すると 
共に,これの熱処理過程における変化について調 ベた。さらに, 医薬品用注射剤中の HA の結果に ついても併せて報告する。

\section{2. 実験}

\section{1 装置および分析条件}

SEC/LALLS 装置は東ソー製であり, CCPD ポ ンプ, $1.0 \mathrm{ml}$ ループインジェクターを付けた AS8000 オートサンプラー, CO-8000 カラム恒温槽, $0.45 \mu$ ラインフィルター, 示差屈折検出計 $(\mathrm{RI}) を$ 内蔵したLS-8000 LALLSを接続した。インテグ レーターはNEC PC 9801 を使用した。検討した カラムは $5 \mu$ ゲルを充填した内径 $7.8 \mathrm{~mm}$, 長さ $30 \mathrm{~cm}$ の水系カラムである TSK gel G6000PW $\mathrm{xL}$ (デキストラン換算による排除限界分子量 $5 \times 10^{7}$ ), $\mathrm{G}_{4000 \mathrm{PW}} \mathrm{xL}\left(\right.$ 同 $\left.1 \times 10^{6}\right), \mathrm{G}^{3} 000 \mathrm{PW}_{\mathrm{xL}}\left(\right.$ 同 $\left.2 \times 10^{5}\right)$, $\mathrm{G} 2500 \mathrm{PW}_{\mathrm{xL}}\left(\right.$ 同 $\left.5 \times 10^{3}\right)$ の 4 種である。

溶離液は $0.2 \mathrm{M}$ 硫酸ナトリウム水溶液を調製し, $0.45 \mu \mathrm{m}$ と $0.2 \mu \mathrm{m}$ のフィルターで吸引濾過し, 流速 $1.0 \mathrm{ml} / \mathrm{min}$ とした。カラム温度は $40^{\circ} \mathrm{C}$ に設 定した。

\section{2 試料}

SECによる検量線作成用標準試料のポリエチ レンオキシド 3 種は東ソー製, プルラン 4 種は昭 和電工製を用いた。試料は化粧品用として当社製 も含めて 7 社 8 種の HA 粉末および医薬品用注射 剤として4社の HA 製剤を測定した。SECへの 試験溶液の調製は粉末の場合, 約 $250 \mathrm{ppm}$ とな るように溶離液に溶解した。注射剤の場合は表示 濃度に対して同じく約 $250 \mathrm{ppm}$ となるように溶 離液に希釈した。これらを試験溶液として $100 \mu 1$ 注入した。

\section{3 粘度平均分子量の測定}

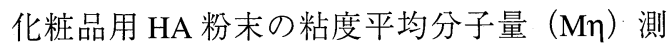
定には, 別に乾燥減量を測定し4), ウベローデ型 粘度計により 4 濃度水準で測定して極限粘度を求

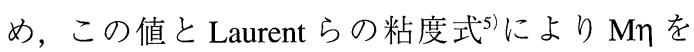
算出した。

\section{3. 結果および考察}

\section{1 カラム条件の検討}

$\mathrm{HA}$ のような高分子電解質の水系 SEC の場合, 固定相であるゲルと溶質とのイオン間相互作用で ある排斥効果のために，高分子用カラムを用いて も排除限界付近に溶出し, 正確な分子量分布が求 められないことが多い。本分析では, 基本的に Beaty らの方法 ${ }^{6}$ に従った溶離液条件を採用して 相互作用を小さくすると共に，使用するカラムの 適正化について検討した。先ず，当社製 HA（M $\left.=1.9 \times 10^{6}\right)$ を試料として, 低分子量から高分子 量までを対象とする目的で, TSK gel G6000PW $\mathrm{G} 4000 \mathrm{PW} \mathrm{xL}_{\mathrm{xL}}, \mathrm{G} 3000 \mathrm{PW} \mathrm{xL}_{\mathrm{xL}}, \mathrm{G} 2500 \mathrm{PW} \mathrm{xL}_{\mathrm{x}}$ カラムの 各 1 本ずつを連結して測定したときのクロマトグ ラムを Fig.ー1 に示す。また，このときの RI と LS のピーク強度比から求まる分子量を保持時間に対 してプロットした結果を Fig.-2に示す。クロマ トグラムからの判断では妥当な分布を示している と思われるが, Fig. - -2 の結果からでは保持時間 26 分までは時間と共に溶出する HA の分子量は低下 しているものの, 27 分以降は逆に分子量が増加 している。これは試料のカラムへの吸着が起きて いるためと思われ, 次に最も大きな排除限界分子 量を示す G6000PW $\mathrm{xL}$ カラムを 4 本連結して同じ 測定を行った。結果をFig.ー3に示すが, Fig.4 では全般の保持時間の経過と共に分子量の低下 がみられ，サイズ排除原理に見合ったカラム条件

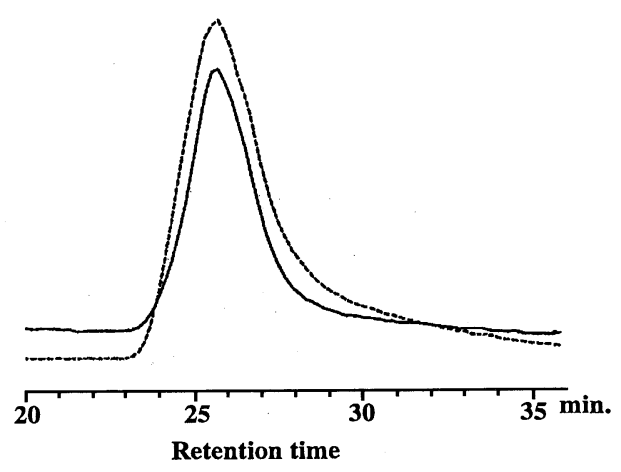

Fig. - 1 Chromatogram of HA on TSK gel G6000PW ${ }_{\mathrm{XL}}$, $\mathrm{G}_{4000 \mathrm{PW}}$, G3000PWXL, and G2500PWXL columns RI, LS 


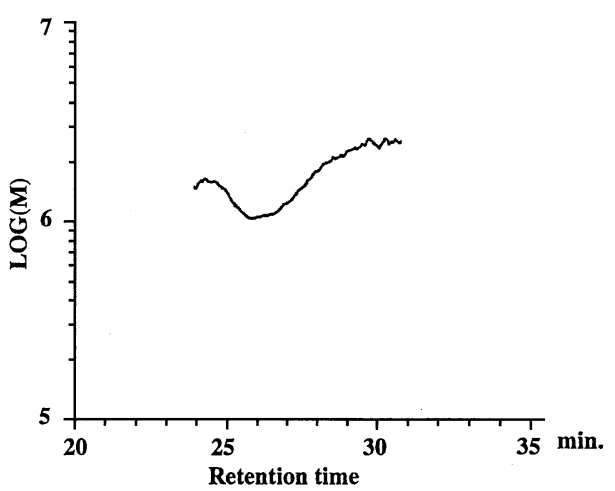

Fig.-2 Relationship between retention time and logarithm of the molecular weight of HA using TSK gel G6000PW $\mathrm{XL}_{\mathrm{X}}, \mathrm{G} 4000 \mathrm{PW} \mathrm{XL}, \mathrm{G} 3000 \mathrm{PW} \mathrm{XL}_{\mathrm{X}}$ and G2500PW $\mathrm{XL}$ columns

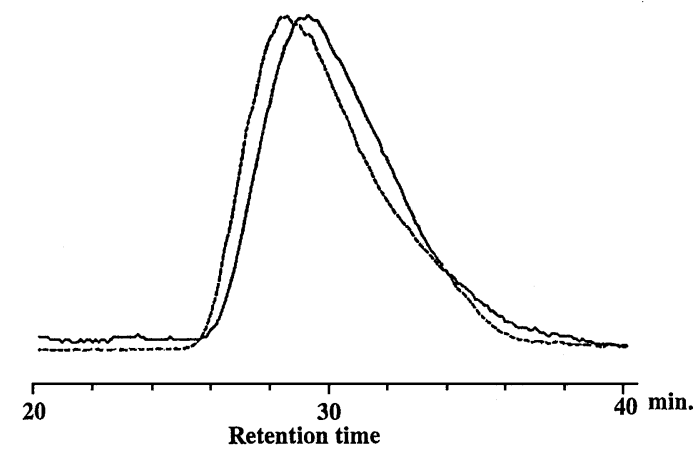

Fig. - 3 Chromatogram of HA on 4 TSK gel G6000PW XL columns

RI, - -

の適正化が行われていることがわかった。これら の結果より以後の測定においては $\mathrm{G} 6000 \mathrm{PW}$ xL ラムを 4 本用いることとした。本分析条件による 分子量測定值の妥当性を評価するために，既知



Fig. - 4 Relationship between retention time and logarithm of the molecular weight of HA using 4 TSK gel G6000PW $\mathrm{XL}$ columns

$\mathrm{Mw}$ のポリエチレンオキシド 3 種とプルラン 4 種 の $\mathrm{Mw}$ 測定を行って比較した。この結果を Table1 に示すが，測定值と表示 $\mathrm{Mw}$ とは良く一致し た。著者らの経験によれば，平均分子量が $3 \times 10^{6}$ 以上になるとさらにカラムの本数を増やさなけれ ばならないことを経験している。

\section{$3.2 H A$ の低分子化による分子量分布の変化}

HA の特性は分子量に大きく依存するために, これに関する情報を得ると共に分子量を使用目的 に従って制御する技術もまた重要である。そこで, 熱処理によるHAの分子量変化について検討した。 当社製 $\mathrm{HA}$ を $70^{\circ} \mathrm{C}$ の減圧乾燥器 $(720 \mathrm{mmHg})$ 内 で 2.5 時間まで加熱処理したときの経時による分 子量変化の様子を Table-2に示す。この結果よ り未処理と比較して 0.5 時間までは変化がみられ ないが，それ以降になると Mw は直線的に減少 する一方で, 分散度 $(\mathrm{Mw} / \mathrm{Mn})$ は直線的な増加 傾向が認められた。さらに，106 単位での分子量

Table-1 Average molecular weight $(\mathrm{Mw})$ of standard samples on polyethylene oxide and pullulan

\begin{tabular}{|c|c|c|c|}
\hline \multicolumn{2}{|c|}{ Standard sample } & \multirow{2}{*}{$\begin{array}{c}\text { Measured Mw } \\
21.2 \times 10^{4}\end{array}$} & \multirow{2}{*}{$\frac{\text { Certificated Mw }}{27.0 \times 10^{4}}$} \\
\hline Polyethylene oxide S & $S E-30$ & & \\
\hline & $\mathrm{SE}-70$ & $53.0 \times 10^{4}$ & $57.0 \times 10^{4}$ \\
\hline & $S E-150$ & $72.9 \times 10^{4}$ & $86.0 \times 10^{4}$ \\
\hline \multirow[t]{4}{*}{ Pullulan } & $\mathrm{P}-200$ & $9.3 \times 10^{4}$ & $10.0 \times 10^{4}$ \\
\hline & $P-400$ & $34.9 \times 10^{4}$ & $38.0 \times 10^{4}$ \\
\hline & P-800 & $90.0 \times 10^{4}$ & $85.3 \times 10^{4}$ \\
\hline & $\mathrm{P}-1800$ & $19.3 \times 10^{5}$ & $18.8 \times 10^{5}$ \\
\hline
\end{tabular}


Table-2 Molecular weight change of HA degraded under heat treatment at $70^{\circ} \mathrm{C}$

\begin{tabular}{|c|c|c|c|c|}
\hline & Untreated & $0.5 \mathrm{~h}$ & $1.5 \mathrm{~h}$ & $2.5 \mathrm{~h}$ \\
\hline Average molecular weight & $2.59 \times 10^{6}$ & $2.65 \times 10^{6}$ & $2.27 \times 10^{6}$ & $1.73 \times 10^{6}$ \\
\hline $\mathrm{Mw} / \mathrm{Mn}$ & 1.07 & 1.08 & 1.35 & 1.74 \\
\hline $\begin{array}{l}\text { Fractional range of } \\
\text { molecular weight }\end{array}$ & \multicolumn{4}{|c|}{$\begin{array}{c}\text { Distribution of molecular weight }(\%) \\
\{\text { Degree of depolymerization }(\%)\}\end{array}$} \\
\hline$\sim 1 \times 10^{6}$ & 0 & 0 & $6^{6}$ & $\begin{array}{l}16 \\
\{22\}\end{array}$ \\
\hline $1 \times 10^{6} \sim 2 \times 10^{6}$ & 11 & 11 & $\begin{array}{l}46 \\
\{55\}\end{array}$ & $\begin{array}{l}60 \\
\{60\}\end{array}$ \\
\hline $2 \times 10^{6} \sim 3 \times 10^{6}$ & 76 & 75 & $\begin{array}{l}40 \\
\{67\}\end{array}$ & $\begin{array}{l}20 \\
\{80\}\end{array}$ \\
\hline $3 \times 10^{6} \sim 4 \times 10^{6}$ & 9 & 9 & $\begin{array}{l}5 \\
\{40\}\end{array}$ & $\begin{array}{l}4 \\
\{100\}\end{array}$ \\
\hline $4 \times 10^{6} \sim$ & 4 & 5 & 3 & 0 \\
\hline
\end{tabular}

分画範囲における低分画への移行率をみると, 処 理時間が $0.5 \sim 1.5$ 時間まではランダムであるが， 1.5 2.5 時間までになると分子量依存性がみられ, 高分子量になるにつれて移行率が高くなり，低分 子化が促進されることが認められた。故に, 熱処 理による HAの低分子化の際には, ある程度の時 間をとって処理すれば高分子量のものは急速に低 分子化されるが, 分布の中心が割れるようなこと はなく，ブロードな多分散ピークを示すことがわ かった。

\section{3 化粧品用HA粉末の分析}

各社化粧品用 HA 粉末 8 種について SEC/ LALLS 測定すると共に, M れらの結果を Table-3にまとめた。測定した M はすべて $1 \times 10^{6} \sim 2 \times 10^{6}$ までに揃っており, SEC/ LALLS 測定結果から求めた Mw と比較して大き
く逸脱しているものがないことから，これらの HA 粉末の純度はいずれも高いものと推定された。 また Table-3 中の $\mathrm{G}$ と $\mathrm{H}$ は同一メーカーの分子 量グレードが異なるものであるが，Mwの差が明 確に測定された。8 種の中から代表として，A〜 $\mathrm{C}$ および G についてのクロマトグラムを Fig. -5 に示す。これより $\mathrm{B} て ゙ は$ 他の 7 種にみられない 分子量分布のピークを二つもつクロマトグラムが 得られた。これは先の検討結果 3.2 から考えて, 異なる分子量分布をもつ 2 種の HA が混合された ものであることが示唆された。

\section{4 医薬品用 HA 注射剂の分析}

各社 HA 注射剂 4 種について SEC/LALLS 測定 を行った。HA 処方の化粧品では他の高分子成分 が共存する場合にはHAの選択的な抽出などの前 処理操作が必要となるが7), HA 注射剂ではいず

Table- 3 Molecular weight data of cosmetic grade HA powders

\begin{tabular}{cccc}
\hline Sample & $\begin{array}{c}\text { Viscosity average } \\
\text { molecular weight }\end{array}$ & Average molecular weight & Mw/Mn \\
\hline A & $1.38 \times 10^{6}$ & $1.49 \times 10^{6}$ & 2.61 \\
B & $1.74 \times 10^{6}$ & $1.52 \times 10^{6}$ & 2.10 \\
C & $1.24 \times 10^{6}$ & $1.36 \times 10^{6}$ & 1.49 \\
D & $1.47 \times 10^{6}$ & $1.55 \times 10^{6}$ & 1.54 \\
E & $1.72 \times 10^{6}$ & $1.74 \times 10^{6}$ & 2.16 \\
F & $1.82 \times 10^{6}$ & $1.74 \times 10^{6}$ & 1.30 \\
G & $1.47 \times 10^{6}$ & $1.32 \times 10^{6}$ & 1.51 \\
H & $1.97 \times 10^{6}$ & $2.17 \times 10^{6}$ & 1.32 \\
\hline
\end{tabular}




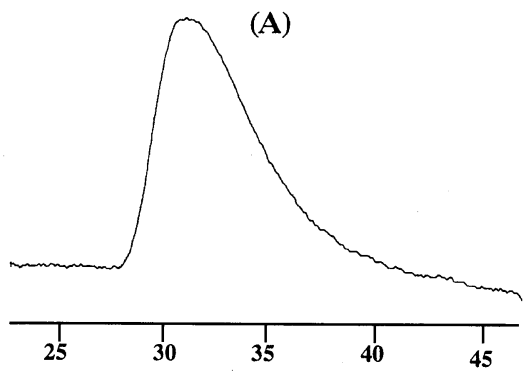

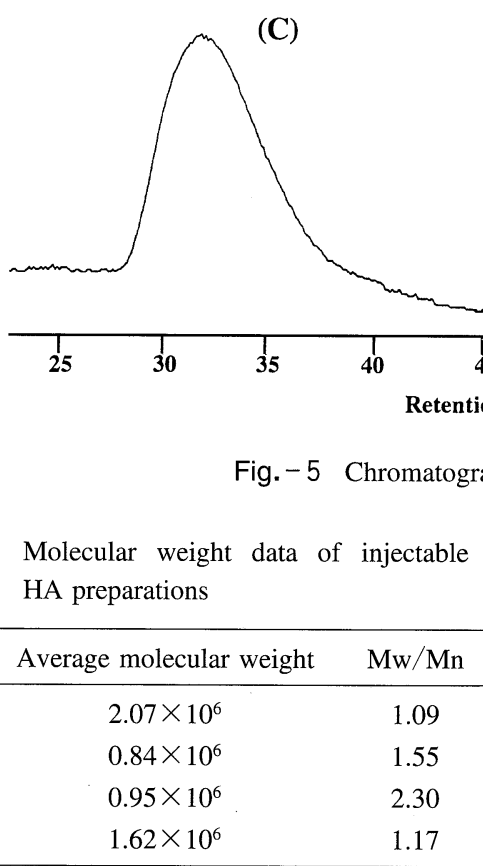

れも共存する高分子成分はなく，溶離液で希釈す るだけの簡便な前処理のみで分析が可能であった。 製剂においても HA の溶出を妨害する成分はみら れず，良好なクロマトグラムが得られ，測定した 分子量結果を Table-4に示した。4 種の中では $\mathrm{W}$ が最も高い Mwを示し，且つ分布が最も単分 散を示した以外に，分子量に関しては先の化粧品 用HA とあまり変わらない結果であった。

\section{4. 結 論}

SEC/LALLS によりHA の市販化粧品用粉末お よび注射剤について分子量的評価を行った。用い た水系カラムは最も大きな排除限界分子量を示す ものを 4 本連結することにより高分子部分が排除

Table-4 Molecular weight data of injectable

\begin{tabular}{ccc}
\hline Sample & Average molecular weight & $\mathrm{Mw} / \mathrm{Mn}$ \\
\hline $\mathrm{W}$ & $2.07 \times 10^{6}$ & 1.09 \\
$\mathrm{X}$ & $0.84 \times 10^{6}$ & 1.55 \\
$\mathrm{Y}$ & $0.95 \times 10^{6}$ & 2.30 \\
$\mathrm{Z}$ & $1.62 \times 10^{6}$ & 1.17 \\
\hline
\end{tabular}

\section{侖}

(B)

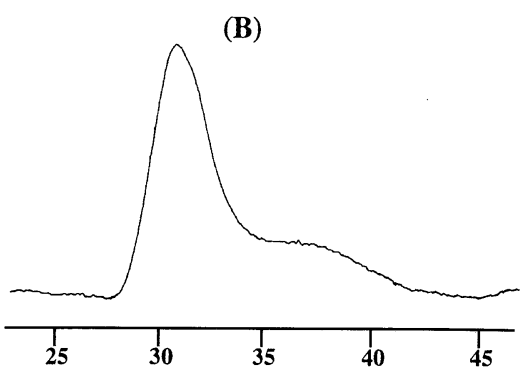

(G)

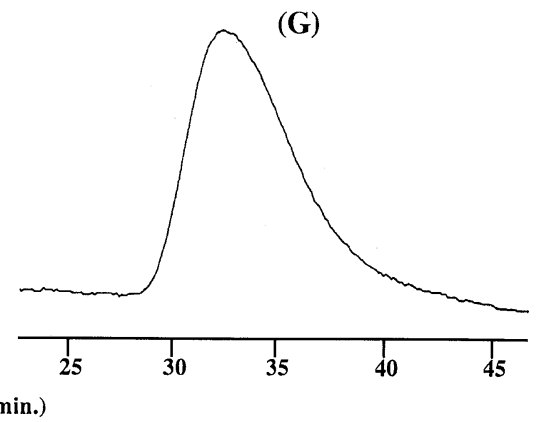


規格, 薬事日報社 (1993) p.760

5) T. C. Laurent, M. Ryan, A. Pletruszkiewicz, Biochim. Biophys. Acta, 42, 476 (1960)

6) N. B. Beaty, W. P. Tew, R. J. Mellow, Anal. Bio- chem., 147, 387 (1985)

7）山本信也, 太田忠男, 森川良広, 分析化学, 31, 251 (1982)

\title{
Measurement of Molecular Weight Distribution of Hyaluronic Acid by Size Exclusion Chromatography Using Low-angle Laser Light Scattering $\dagger^{\prime}$
}

\author{
Mitsuru Shibutani, Taeko Oishi, Shinya Yamamoto, Susumu Hasebe \\ Pharmaceutical Department, Shiseido Kakegawa Factories $\dagger^{2}$
}

The molecular weight distribution and average molecular weight (Mw) of hyaluronic acid (HA) powders and their injectable preparations were measured by size exclusion chromatography/low-angle laser light scattering (SEC/LALLS). The columns used were TSK gel G6000PW $\mathrm{xL}(30 \mathrm{~cm} \times 4)$ made from cross-linked hydrophilic polymers, and were eluted with $0.2 \mathrm{M}$ sodium sulfate at a flow rate of $1.0 \mathrm{ml} / \mathrm{min}$. A reasonable relationship between the retention time and the molecular weight of the HA was obtained under these SEC conditions. The degree of depolymerization of $\mathrm{HA}$ by heating at $70^{\circ} \mathrm{C}$ was related to the molecular weight, it was found to be more extreme the higher the original molecular weight. The measured value of $\mathrm{Mw}$ was in good agreement with the viscosity average molecular weight in eight kinds of cosmetic grade HA powders. The preparation from an injectable HA preparation was conveniently made by diluting with the mobile phase which was directly injected into the SEC. Among examined eight kinds of cosmetic grade HA powders and four injectable HA preparations, HA from an injection showed the lowest degree of polydispersity. It was revealed that SEC/ LALLS was a useful tool for examining the molecular weight distribution of HA and its related medicines.

Key words : hyaluronic acid, molecular weight, size exclusion chromatography, low-angle laser light scattering, degree of depolymerization, heat treatment, cosmetic raw material, injectable preparation 